\title{
PENGARUH KONSUMSI PISANG AMBON TERHADAP PENURUNAN TEKANAN DARAH PADA PRALANSIA YANG MENGALAMI HIPERTENSI DI DUSUN VIII DESA TEMBUNG
}

\author{
Bernita Silalahi.S.Pd.,S.Kep.,M.Kes, Winda Aswani Harahap \\ Dosen Prodi S1Keperawatan, STIKes Imelda, Jalan Bilal Nomor 52 Medan; \\ Alumni STIKes Imelda \\ E-mail: bernitasilalahi01@gmail.com
}

\begin{abstract}
ABSTRAK
Memasuki usia lanjut atau pra lansia terutama pada wanita mulai mengalami penurunan fungsi salah satunya pada sistem peredaran. Dimana terjadi penurunan dinding pembuluh darah yang menyebabkan peningkatan tekanan darah pada lanjut usia. Salah satu cara upaya peningkatan yaitu dengan cara mengkonsumsi pisang ambon karena didalam buah tersebut terdapat kandungan kalium yang cukup tinggi untuk menetralkan natrium dalam darah sehingga dapat menurunkan tekanan darah. Tujuan dari penelitian ini untuk mengetahui pengaruh konsumsi pisang ambon terhadap penurunan tekanan darah pada pra lansia yang mengalami hipertensi. Metode penelitian yang digunakan adalah QuasyEksprimen dengan desaign penelitian one group pre test and post test dimana dalam penelitian ini tidak ada kelompok pembanding dengan responden 30 orang. hasil uji penelitian ini menggunakan uji Mc Nemar $(<0,05)$ didapat nilai penurunan tekanan darah sebelum konsumsi pisang ambon $(3,33 \%)$ dan sesudah konsumsi pisang ambon (93,33\%) maka didat hasil Sig 0,00 (nilai p).kesimpulan adanya pengaruh konsumsi pisang ambon terhadap penurunan tekanan darah pada pra lansia yang mengalami hipertensi di Desa tembung Dususn VII tahun 2018.
\end{abstract}

Kata kunci: pisang ambon, penurunan tekanan darah, pra lansia, Hipertensi.

\section{PENDAHULUAN}

Penyakit darah tinggi (hipertensi) adalah suatu keadaan dimana seseorang mengalami peningkatan tekanan darah diatas normal yang ditunjukkan angka systol (bagian atas) dan angka diastolic (bagianbawah), Seseorang dikatakan menderita hipertensi apabila memiliki tekanan darah sitolik $>140$ $\mathrm{mmHg}$ atau tekanan diastolik $>90 \mathrm{mmHg}$. Sedangkan secara kesehataan nilai normal tekanan darah adalah $120 / 80 \mathrm{mmHg}$. Hipertensi biasanya disebabkan oleh faktor genetik, stres, kurang berolahraga, komsumsi natrium yang berlebihan seperti pola hidup yang tidak baik (Ratna dewi, 2011).

Di Indonesia, hipertensi merupakan penyebab kematian nomor tiga setelah stroke dan tuberkulosis, yakni mencapai $6,7 \%$ dari populasi kematian pada semua umur. Hasil Riset Kesehatan Dasar (Riskesdas) tahun 2007 menunjukan prevalensi hipertensi secara nasional mencapai $31,7 \%$ dan sebagian besar kasus hipertensi di masyarakat belum

terdeteksi (WHO, 2013). Menurut National B asic Health Survey 2013, di Provinsi Sumatra Urtaraprevalensi hipertensipada kelompok usia 45-54 tahun 35,6\%, 55-64 tahun 45,9\%, 65-74 tahun 57,6\%, dan lebih dari 75 tahun adalah $63,8 \%$. Pra lansia adalah sesoorang yang berusia 45-60 tahun. Seiring bertambahnya usia vaskularisasi pembuluh darah akan menurun maka resiko terkena hipertensi menjadi lebih besar (Profil Dinkes Provinsi Sumatra Utara, 2013). Food and drug administration Amerika Serikat menyebut pisang sebagai sumber kalium (350 $\mathrm{mg})$ dan rendah natrium $(140 \mathrm{mg})$ yang ampuh mengurangi resiko tekanan darah tinggi dan stroke. Sebuah pisang mengandung sekitar $487 \mathrm{mg}$ kalium atau menyediakan $14 \%$ kebutuhan sehari. Kandungan kalium pada pisang cukup tinggi, kadarnya bervariasi tergantung jenis pisangnya. Maka dari itu pisang ambon sangat baik dikonsumsi bagi penderita hipertensi karna memiliki kadar kalium yang cukup tinggi (Alini, 2015)

Buah pisang terutama pisang ambon hampir tidak mengandung natrium, tetapi banyak mengandung kalium serta B6, C, dan E. 
Vitamin E dan kalium berkhasiat menurunkan tekanan darah dan menjaga kecantikan .Selain itu, kandungan kalium dalambuah ini berfungsi untuk menyeimbang kan kadar air dalam tubuh, menurunkan teknan darah dan membantu membawa oksigen ke otak. Hemiselulosa pada pisang membantu proses pembuangan lemak dalam darah (Made Astawan, 2013) Dalam penelitian Alini, 2015 menyatakan bahwa pisang ambon juga banyak mengandung serat, sehingga kalium, magnesium dan kalsium yang terkandung dalam pisang ambon dapat di serap baik sehingga mampu menurunkan tekanan darah. Begitu pula hasil kesimpulan dari penelitian Eny Sutria dkk, menyimpulkan bahwa pisang ambon bermanfaat untuk menurunkan tekanan darah dalam tubuh.

Berdasarkan survei awal yang dilakukan di Desa Tembung Dusun VIII Kecamatan Percut Sei Tuan, angkakejadian hipertensi sebanyak 63 orang. Dari latar belakang diatas, maka perlu dilakukan penelitian guna mengetahui adakah pengaruh konsumsi pisang ambon terhadap penurunan tekanan darah pada pra lansia yang mengalami Hipertensi sedang di Desa Tembung Dusun VIII tahun 2018.

\section{Rumusan Masalah}

Pengaruh konsumsi pisang ambon terhadap penurunan tekanan darah pada pra lansia yang mengalami Hipertensi di desa Tembung Dusun VIII tahun 2018.

\section{Tujuan Penelitian}

1. Mengidentifikasi warga dusun VIII desa tembung sebelum mengkonsumsi pisang ambon

2. Megidentifikasi warga dusun VIII desa tembung sesudah mengkonsumsi pisang ambon.

\section{METODE}

Desain penelitian adalah Quasy eksperimen Dengan pendekatan oprasional. $\mathrm{R}$ ancangan penelitian yang digunakan One Group Pre Test and Post test Desain. Tujuan untuk mengetahui pengaruh konsumsi pisang ambon dapat menurunkan tekanan darah pada pra lansia yang mengalami hipertensi sedang di desa tembung dusun viii kecamatan percut sei tuan.

\section{Populasi}

Seluruh warga Desa Tembung Dusun VIII yang mengalami Hipertensi pada pra lansia berjumlah 63 orang.

\section{Sampel}

Menggunakan teknik non probability sampling dengan pendekatan purposive sampling dengan kriteria inklusi peneliti.

Kriteria inklusi penelitian adalah :

1. Usia 45-59 tahun

2. Bersedia menjadi responden dalam penelitian dan menyetujui informed contest

3. Mampu berkomunikasi verbal dan memahami Bahasa Indonesia

4. Bertempat tinggal di Desa Tembung Dusun VIII

5. Memiliki tekanan darah tinggi atau hipertensi.

Dari kriteria yang ada maka diambil sampel dari populasi yang memenuhi kriteria yaitu 30 orang.

\section{Lokasi Penelitian}

Lokasi penelitian Desa Tembung Dusun VIII Kecamatan Percut Sei Tuan.

\section{Waktu Penelitian}

Penelitian dilakukan pada bulan Maret Juli 2018.

\section{Definisi Operasional}

1. Kandungan kalium dipisang ambon: jumlah kandungan elektrolit:kalium pada pisang ambon yang dikonsumsi dua kali sehari yang bermanfaat untuk menetralkan natrium dalam darah.

2. Penurunan tekanan darah terjadinya perubahan sistol dan diastol dari yang tinggi kerendah.

\section{Pengukuran Tekanan Darah}

Aspek pengukuran tekanan darah dilakukan dengan mengunakan Sphygmoman ometer yang berstandart ISO (internasional organization for standarizatio $n$ ) yang telah diuji keakuratannya. 


\section{Metode Pengumpulan Data}

\section{Data Primer}

Data yang didapat dari responden yang mengalami hipertensi sedang pada pra lansia di Desa Tembung Dusun VIII Kecamatan percut Sei Tuan Kabupaten Deli serdang.

2. Data Sekunder

Data yang di dipat dari puskesmas percut sei tuan

3. Data Tersier

Data yang diperoleh dari buku dan jurnal yang telah dipublikasikan.

\section{Pengelolahan Data}

1. Editing

2. Coding

3. Tobulating

4. Entry data

\section{Analisa Data}

1. Analisis Univariat

2. Analisi bivariat

\section{HASIL}

Tabel 1. Distribusi Frekuensi Responden

Berdasarkan Umur, Jenis Kelamin, Pekerjaan, Dan Pendidikan Responden 2018 $(\mathrm{N}=30)$

\begin{tabular}{|c|c|c|c|}
\hline $\begin{array}{l}\mathbf{N} \\
\mathbf{0}\end{array}$ & Umur & Frekuensi & $(\%)$ \\
\hline 1. & $45-49$ & 8 & 27 \\
\hline 2. & $50-54$ & 10 & 33 \\
\hline 3. & $55-59$ & 12 & 40 \\
\hline & Total & 30 & 100 \\
\hline $\begin{array}{l}\mathbf{N} \\
\mathbf{0}\end{array}$ & $\begin{array}{c}\text { Jenis } \\
\text { Kelamin }\end{array}$ & Frekuensi & $(\%)$ \\
\hline 1 & Laki-laki & 7 & 23 \\
\hline 2 & Perempuan & 23 & 77 \\
\hline & Total & 30 & 100 \\
\hline $\begin{array}{l}\mathbf{N} \\
\mathbf{0}\end{array}$ & Pendidikan & Frekuensi & $(\%)$ \\
\hline 1. & $\mathrm{SD}$ & 6 & 20 \\
\hline 2. & SMP & 5 & 17 \\
\hline 3. & SMA & 19 & 63 \\
\hline 4. & Sarjana & 0 & 0 \\
\hline & Total & 30 & 100 \\
\hline $\begin{array}{l}\mathbf{N} \\
\mathbf{0}\end{array}$ & Pekerjaan & Frekuensi & $(\%)$ \\
\hline 1. & $\begin{array}{c}\text { Tidak } \\
\text { bekerja/IRT }\end{array}$ & 15 & 50 \\
\hline 2. & Pedagang & 9 & 30 \\
\hline 3. & PNS & 0 & 0 \\
\hline 4. & $\begin{array}{c}\text { Pegawai } \\
\text { swasta }\end{array}$ & 6 & 20 \\
\hline
\end{tabular}

Hasil penelitian yang diperoleh, dapat diihat bahwa jumlah responden berdasarkan umur mayoritas umur tertinggi 55-59 tahun sebanyak 12 orang $(40 \%)$ dan berdasarkan jenis kelamin mayoritas perempuan sebanyak 23 orang (77\%) sedangkan mayoritas pendidikan SMA sebanyak 19 orang (63\%), dan mayoritas pekerjaan yaitu tidak bekerja atau ibu rumah tangga sebanyak 15 orang $(50 \%)$.

\section{Hasil Univariat}

Tabel. 2 Lemba Observasi Sebelum dan Sesudah KonsumsiPisang Ambon

\begin{tabular}{|c|c|c|c|c|}
\hline \multicolumn{3}{|c|}{ Pre Test } & \multicolumn{2}{|c|}{ Post Test } \\
\hline No & Sistol & Diastol & Sistol & Diastol \\
\hline 1. & 140 & 85 & 130 & 80 \\
\hline 2. & 140 & 85 & 130 & 80 \\
\hline 3. & 140 & 85 & 130 & 80 \\
\hline 4. & 140 & 85 & 130 & 80 \\
\hline 5. & 140 & 85 & 130 & 80 \\
\hline 6. & 145 & 85 & 140 & 80 \\
\hline 7. & 145 & 85 & 140 & 80 \\
\hline 8. & 145 & 85 & 140 & 80 \\
\hline 9. & 145 & 85 & 140 & 80 \\
\hline 10 & 145 & 85 & 140 & 80 \\
\hline 11 & 150 & 85 & 145 & 80 \\
\hline 12 & 150 & 85 & 145 & 80 \\
\hline 13 & 150 & 85 & 145 & 80 \\
\hline 14 & 150 & 90 & 145 & 85 \\
\hline 15 & 150 & 90 & 145 & 85 \\
\hline 16 & 150 & 90 & 145 & 85 \\
\hline 17 & 155 & 90 & 150 & 85 \\
\hline 18 & 155 & 90 & 150 & 85 \\
\hline 19 & 155 & 90 & 150 & 85 \\
\hline 20 & 155 & 90 & 150 & 85 \\
\hline 21 & 155 & 90 & 150 & 85 \\
\hline 22 & 155 & 90 & 150 & 85 \\
\hline 23 & 160 & 95 & 155 & 90 \\
\hline 24 & 160 & 95 & 155 & 90 \\
\hline 25 & 160 & 95 & 155 & 90 \\
\hline 26 & 165 & 100 & 160 & 95 \\
\hline 27 & 170 & 100 & 165 & 95 \\
\hline 28 & 170 & 100 & 165 & 96 \\
\hline 29 & 175 & 110 & 175 & 110 \\
\hline 30 & 176 & 110 & 175 & 110 \\
\hline
\end{tabular}

Berdasarkan tabel diatas selisih tekanan darah sebelum dan sesudah konsumsi pisang ambon selama 6 hari dengan frekuensi $2 \mathrm{x}$ sehari (350 mg) dengan jangka waktu 10-12 jam, terhadap penurunan tekanan darah pra lansia yang mengalami hipertensi adalah 
tekanan darah sistolik $10 \mathrm{mmHg}$ sedangkan tekanan distolik $5 \mathrm{mmHg}$.

Tabel 3. Kategori Frekuensi Observasi Responden Pre Test TD Pada Pra LansiaYang Mengalami Hipertensi

\begin{tabular}{cccc}
\hline No & Perubahan & Frekuensi & $(\boldsymbol{\%})$ \\
\hline 1 & Meningkat & 2 & 7 \\
2 & Tetap & 28 & 93 \\
3 & Menurun & 0 & 0 \\
\hline & Total & 30 & 100 \\
\hline
\end{tabular}

Penurunan Tekanan Darah Pada Pra Lansia sebelum mengkonsumsi pisang Mayoritas mengalami peningkatan sebanyak 2 orang $(7 \%)$ dan yang tidak mengalami penurunan atau tetap sebankya 28 orang $(93 \%)$.

Tabel 4. Distribusi Frekuensi Observasi Responden Post Test) TD Pada Pra Lansia Yang Mengalami Hipertensi

\begin{tabular}{cccc}
\hline No & Perubahan & Frekuensi & Persentase \\
\hline 1 & Meningkat & 0 & 0 \\
2 & Tetap & 2 & 7 \\
3 & Menurun & 28 & 93 \\
\hline & Total & $\mathbf{3 0}$ & $\mathbf{1 0 0}$ \\
\hline
\end{tabular}

Hasil yang telah diperolah Pengaruh Konsumsi Pisang Ambon Terhadap Penurunan Tekanan Darah Pada Pra Lansia Yang Mengalami Hipertensi di Desa Tembung Dusun VIII responden sesudah mengkonsumsi pisang Mayoritas mengalami penurunan sebanyak 28 orang $(93 \%)$ dan yang tidak mengalami penurunan hanya 2 orang $(7 \%)$.

\section{Hasil Bivariat}

Tabel 5. Pengaruh Konsumsi Pisang Ambon Terhadap Perubahan Nilai Tekanan Darah Pada Pra Lansia Yang Mengalami Hipertensi

\begin{tabular}{|c|c|c|c|c|c|}
\hline $\begin{array}{l}\mathbf{N} \\
\mathbf{0}\end{array}$ & $\begin{array}{r}\text { Tekana } \\
\text { Darah }\end{array}$ & $\begin{array}{c}\text { Pengukur } \\
\text { an }\end{array}$ & $\begin{array}{c}\text { Mea } \\
\mathbf{n}\end{array}$ & $\begin{array}{c}P \\
\text { value }\end{array}$ & $\mathbf{n}$ \\
\hline \multirow[t]{2}{*}{1} & Sistol & Sebelum & 153 & 0.00 & \\
\hline & & Sesudah & 143 & & \\
\hline \multirow[t]{2}{*}{2} & Diastol & Sebelum & 95 & 0.00 & \\
\hline & & Sesudah & 82 & & \\
\hline
\end{tabular}

Tabel 5. Frekuensi Perbandingan Pre test dan Post test Responden dengan Uji Mc Nemar

\begin{tabular}{lllll}
\hline No & Perubahan & $\begin{array}{l}\text { Pre } \\
\text { Test }\end{array}$ & $\begin{array}{l}\text { Post } \\
\text { Test }\end{array}$ & \\
\hline 1 & Meningkat & 2 & 0 & \\
2 & Tetap & 28 & 2 & 0,000 \\
3 & Menurun & 0 & 28 & \\
\cline { 1 - 3 } & Total & $\mathbf{3 0}$ & $\mathbf{3 0}$ &
\end{tabular}

Hasil uji Mc Nemar berdasarkan tabel lihat pada nilai Sig.nya 0.00 (nilai p). hal ini menunjukkan bahwa nilai $p>0,05$ dengan selisih tekanan darah sistolik $10 \mathrm{mmHg}$ sedangkan tekanan distolik $5 \mathrm{mmHg}$. Maka Ha diterima artinya ada pengaruh yang berarti ada perubahan signifikan antara sebelum dan sesudah diberikan konsumsi pisang ambon terhadap penurunan tekanan darah pada pra lansia yang mengalami hiprtensi di desa tembung dusun VIII Tahun 2018.

\section{PEMBAHASAN}

Berdasarkan hasil penelitian responden berjumlah 30 orang yang sebagian besar responden yaitu pra lansia atau memasuki usia lanjut mayorita umur tertinggi 55-59 tahun berjumlah 12 orang (40\%) dan umur 50-54 tahun berjumlah 10 orang (33\%) dan umur 45-49 tahun berjumlah 8 orang (27\%). Berdasarkan jenis kelamin mayoritas perempuan berjumlah 23 orang (77\%) dan laki-laki berjumlah 7 orang (23\%), sedangkan berdasarkan pendidikan mayoritas pendidikan SMA sebanyak 19 orang (63\%) SMP sebanyak 5 orang (17\%) dan Sd sebanyak 6 orang $(20 \%)$, sedangkan berdasarkan pekerjaan mayoritasnya adalah ibu rumah tangga sebanyak 15 orang $(50 \%)$ dan pedagang sebanyak 9 orang $(30 \%)$ dan pegawai swasta sebanyak 6 orang (20\%). Sebelum dilakukan perlakuan dalam konsumsi pisang ambon peneliti melakukan observasi selama 6 hari dan di dapat nilai peningkatan dan penurunan tekanan darah pada pra lansia yaitu yang mengalami penurunan sebanyak 1 (3\%), dan tidak mengalami penurunan ada 29 orang $(97 \%)$, sedangkan setelah adanya perlakuan sesudah konsumsi pisang ambon selama 6 hari dengan frekuensi $2 \mathrm{x}$ sehari responden yang mengalami penurunan sebanyak 28 orang (93\%) dengan hipertensi stadium I dengan selisih tekanan sistolik $10 \mathrm{mmhg}$ dan tekanan 
diastolik $5 \mathrm{mmHg}$ sedangkan yang tidak mengalami penurunan sebanyak 2 orang $(7 \%)$ dengan hipertensi stadium II. Dimana di buktikan pada hasil penelitian bahwasanya pisang ambon baik dikonsumsi pada

Masyarakat desa tembung dusun VIII yang banyak menggemari makanan yang asin atau mengandung natrium yang cukup tinggi setiap hari nya dapat menaikan tekanan darah. Konsumsi natrium dalam jumlah yang tinggi dapat mengecilkan diameter dari arteri, sehingga jantung harus memompa lebih keras untuk mendorong volume darah yang meningkat melalui ruang yang semakin sempit dan akan menyebabkan tekanan darah meningkat (Brunner dkk,. 2011). Kalium pada prinsipnya terdapat dalam sel-sel tubuh. Fungsi kalium adalah melengkapi fungsi natrium. Maka dari itu pisang ambon sangat baik dikonsumsi setiap harinya, karena kalium pada pisang tersebut dapat menetralkan natrium agar tidak terjadi kenaikan tekanan darah di ikuti dengan olahraga teratur.

Hasil uji statistika Mc Nemar, dimana uji menggunakan statistik non parametrik yang digunakan untuk menguji perbedaan dua sampel berpasangan, bentuk skala nominal, mengukur sebelum dan sesudah perlakuan dan diperoleh hasil dari penelitian ini nilai signifikannya $p=0,000(<0,05)$ yang artinya Ha diterima berarti adanya pengaruh konsumsi pisang ambon terhadap penurunan tekanan darah pada pra lansia yang mengalami hipertensi didesa tembung dusun VIII.

\section{KESIMPULAN}

1. Usia responden 55-59 tahun, jenis kelamin perempuan $(76,7 \%)$, pendidikan SMA $(63,3 \%)$, dan responde yang tidak bekerja/IRT $(50,0 \%)$.

2. Sebagian besar responden dalam penelitian ini mengalami penurunan tekanan darah $(93,33 \%)$, dan tidak mengalami penurunan $(6,67 \%)$ setelah mengkonsumsi pisang.

3. Adanya penurunan tekanan darah sesudah konsumsi pisang ambon selama 6 hari dengan frekuensi $2 \mathrm{x}$ seari $(350 \mathrm{mg})$ tekanan darah sistolik $10 \mathrm{mmHg}$ tekanan dan $5 \mathrm{mmHg}$ tekanan diastolik.

4. uji- Mc Nemar diperoleh $\mathrm{p}=0,000(<0,05)$ menunjukan adanya pengaruh antara penderita hipertensi karena buah tersebut banyak mengandung kalium yang dapat menetralkan natrium dalam darah sehingga dapat menurunkan tekanan darah (Alini, 2016).

variabel konsumbi pisang dengan variabel penurunan tekanan darah.

\section{SARAN}

1. Bagi Institusi (STIKes Imelda)

Hendaknya mengadakan edukasi ataupromosi kesehatan tentang hipertens

i. Dengan cara salah satunya mengkonsumsi pisang ambon dapat menurunan tekanan darah pada pra lansia.

2. Bagi Masyarakat

Dapat mengontrol atau menurunkan tekanan darah dengan mengkonsumsi pis ang ambon setiap harinya dengan frekuensi yang benar.

3. Bagi Peneliti selanjutnya Agar mendalami mengenai konsumsi pisang ambon dapat menurunkan tekanan darah pra lansia yang mengalami hipertensi sehingga hasil penelitian yang didapatkan menjadi lebih baik.

\section{DAFTAR PUSTAKA}

Alini. (2015). Pengaruh Konsumsi Pisang Ambon Terhadap Penurunan Tekanan Darah Pada Klien Lansia Dengan Hipertensi Sedang Dipanti Sosial Tresna Wedrha Khusnu Tahun 2015. Dosen Stikes Tuanku Tambusai Riau.

Arikunto, Suharsini. (2010). Prosedu Penelitian Suatu Pendekatan Praktik. Jakarta: Rineka Cipta

Astawan, Made. (2013). Buah Ajaib Tumpas Penyakit. Jakarta: Penebar Swadaya.

Dinkes Provinsi Sumatra Utara, (2013). Profil Kesehatan Provinsi Sumatra Utara.

Eny Sutria. Aulia Insani. (2010). Pengaruh K onsumsi Pisang Ambon Terhadap

Penurunan Tekanan darah Pra Lansia Hipertensi. Makasar: Fakultas Ke dokteran dan Ilmu Kesehatan, UIN Alau ddin Makasar.

Husdiana. (2014). Patofisiologi Penyakit. Jakarta: Penebar Swadaya. 
Inna Fatmawati, Tuti Rahmawati. (2016). Hubungan Asupan Natrium Dengan Tekanan Darah Pada PasienGagal Ginjal Kronik Yang Menjalani Hemodialisis. Surakarta: Universitas Muhammadiyah.

Ketty Husnia., (2014). Khasiat ajaib Pisang, Yogyakarta: Nuha Medika.

Kushuryadi. (2010). Asuhan Keperawatan Pa da Klien lanjut Usia. Yogyakarta: Salemba Medika.

Notoatmodjo, Soekidjo. (2012). Metode Penelitian Kesehatan, Edisi Refisi Kedua. Jakarta: Rineka Cipta.
Pudiastuti, Ratna Dew. (2011). Penyakit PemicuStroke. Jakarta: Nuha Medika.

Redaksi Argomedia. (2009). Solusi Sehat Mengatasi Hipertensi. Tanggerang:: Redaksi Argomedia.

S.Tarher., (2008). Kesehatan Usia Lanjut dengan Pendekatan Asuhan Keperawata $n$. Jakarta: Nuha Medika.

World Health Organization,(2013). A Global Brief On Hypertension - Silent Killer, Global public crisis: WHO press.

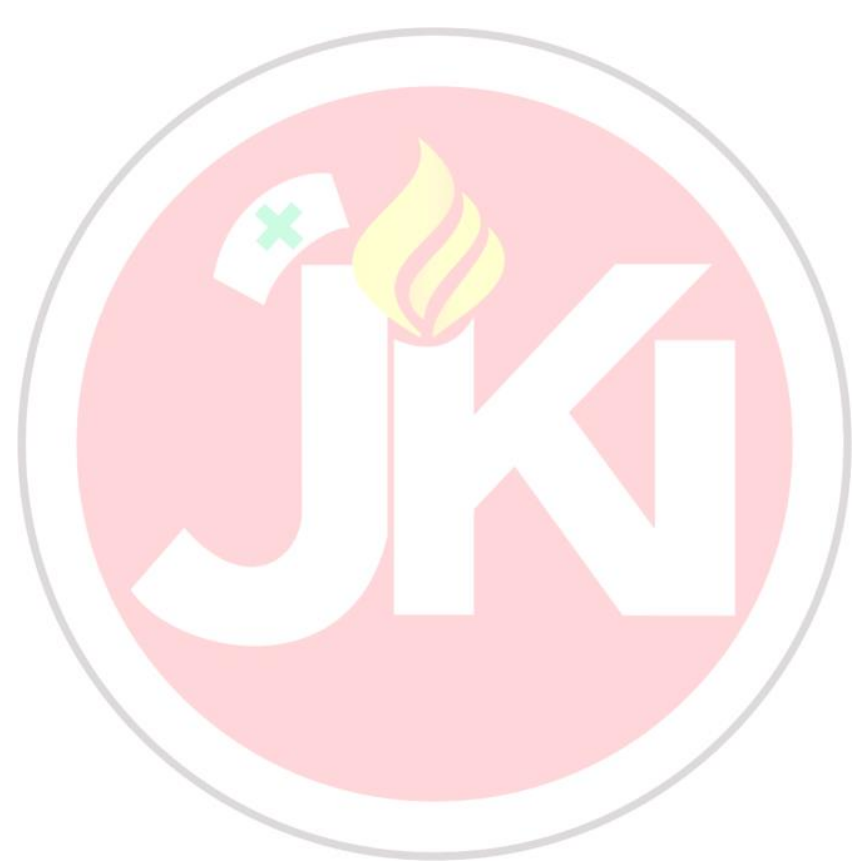

